\title{
A study of the diagnostic value of Inhibin A Tests for occurrence of preeclampsia in pregnant women
}

\author{
Farzaneh Broumand ${ }^{1}$, Shaker Salari Lak ${ }^{2}$, Farhad Nemati ${ }^{3}$, Atefeh Mazidi ${ }^{4}$
}

${ }^{1}$ M.D., Associate Professor of Gynecology, Urmia University of Medical Sciences, Urmia, Iran

${ }^{2}$ Associate Professor of Epidemiology, Department of Public Health, Tabriz Branch, Islamic Azad University, Tabriz, Iran

${ }^{3}$ M.D., Cytopathologist, Nemati Clinical Laboratory, Urmia, Iran

${ }^{4}$ M.D., Gynecologist, Urmia University of Medical Sciences, Urmia, Iran

\section{Type of article: Original}

\begin{abstract}
Background: Hypertensive disorders are common during pregnancy, and are among 3 important causes of maternal death. Preeclampsia occurs in 3 to $5 \%$ of pregnancies. Early diagnosis of this disorder can lead to better pregnancy outcomes.

Objective: The aim of this study was to determine the relationship between inhibin A serum levels during second stage pregnancy screening tests, and incidence and severity of preeclampsia.

Methods: In this study, 300 pregnant women who referred to Kowsar Hospital and carried out second stage pregnancy screening tests from September 2014 to March 2015 in Urmia city, Iran, were enrolled. Five ml venous blood samples were obtained from each participant, and inhibin A serum levels were evaluated in all cases. Finally, all the necessary information was obtained from the pregnancy files of participants after delivery, and gathered in a questionnaire. The data were analyzed using SPSS software version 18 and independent $t$-test, ANOVA and descriptive statistics were used. P-values less than 0.05 were considered significant.

Results: Among the 300 pregnant women who were studied, the gestational age at the time of acquiring blood samples was as follows: 169 cases $(56.3 \%)$ at $16-17$ weeks, 77 cases $(25.7 \%)$ at $18-19$ weeks and 14 cases at 20 weeks $(4.7 \%)$. In this study, MOM of inhibin A was more than 1.25 in 12 cases that finally, preeclampsia occurred in them. This relationship was statistically significant $(\mathrm{p}=0.001)$. The relationship between MOM of inhibin A and severe preeclampsia was evaluated, and the relationship was significant $(p=0.004)$. The relationship between MOM of inhibin A and pregnancy hypertension was not significant $(\mathrm{p}=0.643)$.

Conclusion: Considering the results of this study, we can conclude that MOM of inhibin A levels in maternal serum during second stage pregnancy screening tests can predict incidence and severity of developing preeclampsia in pregnant women. This is not true in cases of pregnancy hypertension.

Keywords: Pre-Eclampsia, Inhibin A, Pregnancy tests, Pre-Eclampsia
\end{abstract}

\section{Introduction}

Preeclampsia (PE) is one of the commonest complications of pregnancy, occurring in 3 to $5 \%$ of pregnancies and is the main source of maternal and newborn child mortality around the world (1). This complication is one type of hypertension unique to pregnancy that can influence any organ $(1,2)$. PE is defined as blood pressure more than or equivalent to $140 / 90(\mathrm{mmHg})$ following 20 weeks of pregnancy with proteinuria more prominent than or equivalent to $300 \mathrm{mg}$ for 24 hours, protein/creatinine proportion more than 0.3 , or a dipstick test result more than or equivalent to +1 . Its rate of occurrence is between 3 to $7 \%$ in nulliparous and 0.8 to $5 \%$ in multiparous, and is especially high in twin pregnancy (2). The complications of PE include disseminated intravascular coagulation, placental abruption, renal failure, severe ascites, pulmonary edema, pleural effusion, cerebral edema, eye problems, and edema of the

\section{Corresponding author:}

Associate Professor Dr. Farzaneh Broumand, Urmia University of Medical Sciences, Urmia, Iran.

Tel: +98.9143412320, Fax:+98.4433197656, Emal:farzaneh.bbb222@gmail.com

Received: August 27, 2017, Accepted: October 30, 2017, Published: January 2018

iThenticate screening: October 18, 2017, English editing: December 12, 2017, Quality control: December 15, 2017

This article has been reviewed / commented by Three experts

(C) 2018 The Authors. This is an open access article under the terms of the Creative Commons Attribution-NonCommercialNoDerivs License, which permits use and distribution in any medium, provided the original work is properly cited, the use is non-commercial and no modifications or adaptations are made. 
larynx, liver hematoma, acute respiratory distress syndrome, and maternal and fetal mortality (2). Early diagnosis of this complication may ease the change of the result of pregnancy by expanding the checking of the malady with early beginning of suitable remedial intercessions (3). For getting the above-mentioned solution, assessment of various biological, biochemical, and biophysical indices associated with PE pathophysiology are suggested in the early stages of pregnancy or during pregnancy to predict the occurrence of this malady. Researchers made efforts to specify indices of early stages of placenta formation, placental perfusion problem, endothelial cell activity, and dysfunction and activation of the coagulation system (1). A spectrum of biochemical markers has been suggested to predict or assess the progress of PE. Endocrine cases used in research for predicting the occurrence of PE syndrome are HCG, $\alpha \mathrm{FP}$, sterol, PAPPA, activin A, Placental B-protein, and CRH $(1,2,4)$. Inhibin, which is one of the markers, is a glycoprotein hormone that belongs to a superfamily of transforming growth factor and is composed of alpha beta A (inhibin A) and alpha beta B (inhibin B) (5). Corpus luteum is known as one of the sources of inhibin A in pregnant women. Recent studies have shown that the origin of inhibin A is a placenta-fetal unit (6). During pregnancy, inhibin A level is greatly higher in maternal serum. Its value falls in early pregnancy from 8 to 13 weeks and 15 to 19 weeks, and then goes up till the peak is reached at the time of the term $(7,8)$. Women with PE have drastically higher levels of activin A, inhibin A, and pro-alpha C (9). Numerous studies have suggested the connection between levels of inhibin A and the process of pregnancy, including that inhibin $\mathrm{A}$ in the maternal circulation is mainly from placental trophoblast during pregnancy (10) as the concentration of maternal inhibin A decreases right away after removal of placenta (9). Furthermore, it has been shown that the increased levels of inhibin A are related to many conditions in the placenta, such as hypoxia, infection, and fetal-placental malformations $(10,11)$. Thus, the measurement of inhibin A during pregnancy may clinically have valuable information for monitoring placental disease $(11,12)$. Studies were conducted in Iran to investigate the relationship between biomarkers and pregnancy outcomes in mothers and fetuses. However, they have not mentioned single inhibin A assessment and its value in predicting PE (13). Thus, the use of inhibin A, which is one of the markers assessed in the second stage of screening, can be considered as a predictive test for the incidence of PE to stop the risk of PE in pregnant women, and with special midwifery care in pregnant women at higher risk, one can take some steps to improve the health of the mother and the newborn. Thus, this study was aimed to determine the relationship between inhibin A serum levels during the second stage pregnancy screening tests and incidence and severity of preeclampsia.

\section{Material and Methods}

\subsection{Research design and participants}

In this study, 300 pregnant women who referred to Kowsar Hospital in Urmia city, Iran from September 2014 to March 2015, were enrolled. The women, who were at the gestational age of 16 to 20 weeks, carried out second stage pregnancy screening tests due to the recommendation of specialists. All subjects who had the above conditions for performing second stage screening tests referred to the lab, and a questionnaire containing the demographic characteristics of each person was recorded, and informed consent was obtained to use the outcomes of their usual tests for research objectives.

\subsection{Selection criteria}

\subsubsection{Inclusion criteria}

Inclusion criteria were lack of multiple pregnancy, history of diabetes, history of PE in previous pregnancies, chronic diseases such as kidney, liver and heart problems, chronic blood pressure, collagen vascular disease and having indication for second stage screening-test recommended by Kowsar hospital specialists in a single laboratory. 2.2.2. Exclusion criteria

Exclusion criteria were awareness of history of diabetes during study, increasing BMI greater than or equal to 35 , and lack of satisfaction to continue the study.

\subsection{Screenings and data collection}

After obtaining informed consent, 5cc of the blood sample of each pregnant woman was procured under sterile conditions, which was a part of the second screening test, and the samples were centrifuged. Then they were placed at $-4{ }^{\circ} \mathrm{C}$ and serum level of inhibin A was measured by Enzyme-linked immunosorbent assay (ELISA) method. All pregnant women in the study were first registered through a questionnaire with specification, contact number and address of the place of residence, previous medical records, and height and weight measurement along with gestational age based on the ultrasound. The second screening step involved a blood test between 14 weeks, and 20 weeks and 6 days. For either blood test, $5 \mathrm{~mL}$ of blood is required in a plain vial with no anticoagulant. The blood can be drawn at any major pathology blood collection center, and is then delivered to the appropriate laboratory with 
an accompanying specific request form. The combined test [maternal serum markers, including $\alpha$-fetoprotein (AFP), free- $\beta$-human chorionic gonadotropin (free- $\beta$-hCG) and unconjugated estriol $\left(\mathrm{uE}_{3}\right)$ or inhibin $A$, combined with gestational age and maternal weight or age] for Down's syndrome (DS) is now well established for singleton pregnant women (14). Finally, all postpartum data were collected through a maternity case of the subjects studied, in a questionnaire containing information such as maternal age, BMI at the beginning of pregnancy, gestational age, delivery reason, delivery method, serum level of inhibin A in the screening tests of the second stage, and blood pressure of delivery. In cases of high blood pressure, accompanied by delivery time, symptoms including headaches, visual impairment, nausea and vomiting, upper abdominal pain, oliguria, or seizures, laboratory information including $\mathrm{CBC}$ and hepatic and renal tests, and the level of urine protein were also recorded. Five ml of venous blood were taken in sterile conditions and used for the second phase of pregnancy screening tests (pregnancy screening tests in the second stage including $\beta \mathrm{hCG}$ tests, a-feto protein, inhibin A, and non-ketamine estradiol, which is measured at the gestational age of 16 to 20 weeks) from all the subjects included in the study, which included the serum level of inhibin A. The data were collected using a questionnaire and using the delivery records of the subjects. The variables studied in this questionnaire included maternal age, BMI at the beginning of pregnancy, gestational age at time of delivery, spontaneous or induced delivery, delivery method, inhibin A serum level in the second stage screening tests, delivery time blood-pressure (maximum blood pressure or average blood pressure last 12 hours before delivery). Symptoms at the time of delivery were headache, visual impairment, nausea and vomiting, upper abdominal pain, oliguria and seizure. In addition, laboratory information including $\mathrm{CBC}$, liver function tests, renal tests and urinary protein levels were also recorded.

\subsection{Data analysis}

Concerning the assessment of predictive value of the inhibin A test for PE, the percentage of sensitivity, specificity, positive predictive value, negative predictive value, the ratio of positive and negative likelihood, and the percentage of agreement reached based on the Kappa statistic, were examined. To calculate sensitivity and specificity, the results of the test were compared with the definitive diagnostic results of PE with confirmed clinical and laboratory measures. Finally, the results were calculated with the critical point of percentile $90 \%$ for data and with MoM $\geqslant 1.25$ sensitivity and specificity of the results. Fisher's exact test was used to measure the relationship between the bivariate quantitative outcome, and Chi-square test was used for multivariate variables. The data were analyzed using SPSS software version 18. P-values less than 0.05 was considered significant.

\subsection{Ethical considerations}

This study was approved by an ethics committee with No. 9401321907. The information used in the study was fully confidential; the participation in this study presented no harm to the mother, or her child. As there was no intervention in this study, and all the measures were parts of the current standard activities for pregnancy period care and its outcome, no cost was imposed on the population sample, and participants entered the study after obtaining an informed consent form.

\section{Results}

In this study, 300 pregnant women were examined. Among the subjects, 6 cases $(2 \%)$ had the experience of a single incidence of intrauterine fetal death. Thirteen cases $(4.3 \%)$ had the experience of one case infant death after birth, 82 cases $(27.3 \%)$ had abortions under the 20th week, of which 56 cases $(18.7 \%)$ had one abortion, 24 cases $(8 \%)$ two abortions, and 2 cases $(0.7 \%)$ three abortions under the 20th week. Thirty-nine pregnancies $(13 \%)$ were completed in less than 37 weeks, and the rest at week 37 and on. Of these 300 subjects, 106 cases (35.3\%) had the termination of pregnancy through induction and 194 had spontaneous deliveries, of which 156 (52\%) were vaginal delivery and $144(48 \%)$ were cesarean delivery. The average weight of infants at delivery was $3228.03 \pm 524.84$ grams: the lowest birth weight was 400 grams and the highest was 4,700 grams. Fifteen cases (5\%) of infants weighed less than 2,500 grams (Table 1). Routine examinations were performed for gestational hypertension and PE during hospitalization of patients. Six patients $(2 \%)$ had gestational hypertension and $14(4.7 \%)$ had PE, of whom $8(2.7 \%)$ had severe symptoms of PE. The prevalence of PE in the studied population was $4.66 \%$. Moreover, 5 cases $(1.7 \%)$ had urinary protein +3 and more, 5 cases $(1.7 \%)$ had intrauterine growth restriction, 8 cases $(2.6 \%)$ had headache, one case $(0.3 \%)$ had blurred vision, 3 cases $(1 \%)$ had epigastric pain symptom, 7 cases $(2.3 \%)$ had nausea and vomiting, and there were no cases of creatinine greater than 1.1 nor were there any cases of oliguria or seizures (Table 2). Moreover, of the whole population, in 15 cases (5\%), infants weighed less than 2,500 grams, of whom 5 cases were in PE infants. (Table 2). Among 107 people with inhibin A of MOM equal to or more than 1.25, 12 subjects (4\%) had PE and of 193 subjects with inhibin A of MOM less than 1.25 , two subjects $(0.7 \%)$ had PE. Thus, $11.21 \%$ of subjects with $\mathrm{MOM} \geq 1.25$ had PE and $1.03 \%$ of those with $\mathrm{MOM}<1.25$ ( $<<0.0001$, Fisher's exact test) (Table 3). 
Table 1. General characteristics of the studied population

\begin{tabular}{|l|l|l|}
\hline Variable & Frequency (\%) \\
\hline Gravidity & $\leq 2$ & $205(68.3)$ \\
\cline { 2 - 3 } & $\geq 3$ & $95(31.7)$ \\
\hline \multirow{3}{*}{ The number of children } & Nulliparous & $138(46)$ \\
\cline { 2 - 3 } & $1-2$ & $154(51.3)$ \\
\cline { 2 - 3 } & $\geq 3$ & $8(2.7)$ \\
\hline \multirow{2}{*}{ Gestational age while taking samples (weeks) } & $16-17$ & $169(56.3)$ \\
\cline { 2 - 3 } & $18-19$ & $77(25.7)$ \\
\cline { 2 - 3 } & 20 & $14(4.7)$ \\
\hline Gestational age during delivery (weeks) & $<37$ & $34(11.3)$ \\
\cline { 2 - 3 } & $\geq 37$ & $266(88.7)$ \\
\hline Delivery method & Vaginal & $156(52)$ \\
\cline { 2 - 3 } & Cesarean section & $144(48)$ \\
\hline Cause of delivery & Induction & $106(35.3)$ \\
\cline { 2 - 3 } & Spontaneous & $194(64.7)$ \\
\hline Infants weight; Mean \pm SD: 3228.03 \pm 524.84 & $<2500$ gr & 400 \\
\cline { 2 - 3 } & $>4500$ gr & 4700 \\
\hline Gestational age (weeks); Mean \pm SD: $38.59 \pm 2.14$ & $<37$ & 24 \\
\cline { 2 - 3 } & $>42$ & 43 \\
\hline
\end{tabular}

Table 2. Total and accumulative frequency of severity of PE complications

\begin{tabular}{|l|l|l|}
\hline Complication & Frequency & $\%$ \\
\hline Systolic blood pressure equal to and above $160 \mathrm{mmHg}$ & 6 & 2 \\
\hline Diastolic blood pressure equal to or greater than $110 \mathrm{mmHg}$ & 4 & 1.3 \\
\hline Platelet less than 100,000 & 1 & 0.3 \\
\hline The transaminase level at least twice the normal value & 1 & 0.3 \\
\hline LDH greater than or equal to 1.5 times the normal value & 1 & 0.3 \\
\hline Protein urine 3+ or more & 5 & 1.7 \\
\hline Restriction of intrauterine growth based on ultrasound diagnosis & 5 & 1.7 \\
\hline Headache symptom & 8 & 4 \\
\hline Blurred vision symptom & 1 & 0.3 \\
\hline Epigastric pain symptom & 3 & 1 \\
\hline Nausea and vomiting & 7 & 2.3 \\
\hline
\end{tabular}

Table 3. The relationship between $\mathrm{MOM} \geq 1.25$ inhibin A and $\mathrm{PE}$

\begin{tabular}{|l|l|l|l|}
\hline \multirow{2}{*}{ Preeclampsia } & Inhibin A \\
\cline { 2 - 4 } & MOM $\geq 1.25$ & MOM $<1.25$ & Total \\
\hline Yes & $12(4 \%)$ & $2(0.7 \%)$ & $14(4.7 \%)$ \\
\hline No & $95(31.7 \%)$ & $191(63.7 \%)$ & $286(95.3 \%)$ \\
\hline Total & $107(35.7 \%)$ & $193(64.3 \%)$ & $300(100 \%)$ \\
\hline \multicolumn{4}{|r}{$p=0.0001$} \\
\hline
\end{tabular}

The Kappa test statistic was 0.014 . The sensitivity of inhibin A with MOM $\geq 1.25$ in predicting PE was $83.83 \%$, its specificity $65.30 \%$, positive predictive value $4.67 \%$, negative predictive value $99.48 \%$, positive likelihood 2.41 , and negative likelihood 0.24 , and its diagnostic accuracy was $65.66 \%$. The value of inhibin A in percentile $90 \%$ was 329 $\mathrm{pg} / \mathrm{ml}$, where $272(90.6 \%)$ subjects had inhibin A less than percentile $90 \%$, and $28(9.3 \%)$ subjects had a high concentration of inhibin A above $90 \%$. Of 272 subjects under $90 \%, 11$ had PE and 28 of them had percentile over $90 \%$, and 3 had PE. This difference with $\mathrm{p}=0.132$ is not statistically significant. Among 6 patients who had gestational hypertension; in 2 cases (33.3\%), the level of inhibin A with $\mathrm{MOM} \geq 1.25$, and in 4 cases (66.7\%), levels of inhibin A with $\mathrm{MOM}<1.25$. From among 294 patients with negative gestational hypertension, in 105 cases (35.7\%), the level of inhibin A was MOM $\geqslant 1.25$, and in 189 cases (64.3\%), the level of inhibin A was MOM $<1.25$. The relationship between the level of inhibin A and gestational hypertension was $p=0.643$ according to Fisher's exact test (Table 4). The Kappa test statistic is 0.904 . The level of inhibin A with MOM $\geq 1.25$ in the prediction of 
gestational hypertension was $33.33 \%$, its specificity was $64.28 \%$, positive predictive value was $1.86 \%$, negative predictive value was $97.92 \%$, positive likelihood was 0.93 and negative likelihood was 1.03 , and finally, its diagnostic accuracy was $63.66 \%$. Among 8 patients with severe symptoms of PE, in 7 cases $(87.5 \%)$, the level of inhibin A was $\mathrm{MOM} \geq 1.25$; and in 1 case (12.5\%) the level of inhibin A was MOM $<1.25$. Among 292 patients with negative gestational hypertension, 100 cases (34.2\%) had level of inhibin A with MOM $\geq 1.25$ and in 192 cases $(65.8 \%)$ levels of inhibin A with $\mathrm{MOM}<1.25$. The relationship between the level of inhibin A and the gestational hypertension based on Fisher's exact test was $(p=0.004)$ (Table 5). The Kappa test statistic is 0.002 . The sensitivity of inhibin A with $\mathrm{MOM} \geq 1.25$ in predicting PE was $87.50 \%$, its specificity $65.65 \%$, positive predictive value $6.54 \%$, negative predictive value $99.48 \%$, positive likelihood 2.54 , and negative likelihood 0.19 , and its diagnostic accuracy was $66.33 \%$. In addition, the mean likelihood ratio for the quadruple test was $1.68 \pm 0.24$ and about $\mathrm{MOM} \geq 1.25$ inhibin A was 2.41 for PE, which showed it was higher in inhibin A compared to the quadruple test. Moreover, Fisher's exact test was used to determine the relationship between the levels of inhibin A with MOM $\geq 1.25$ with evidence of PE severity. The gestational age was less than 37 weeks $(p=0.722)$, delivery method $(p=0.279)$, platelet less than $100000(p=0.357)$, urine protein $+3(p=0.352)$, headache $(p=0.001)$, blurred vision $(p=0.357)$, epigastric pain $(p=0.045)$, nausea and vomiting $(p=0.009)$, weight of the infant less than $2,500 \mathrm{~g}(\mathrm{p}=0.138)$, and intrauterine growth constraint $(\mathrm{p}=0.056)$ was measured (Table 6$)$.

Table 4. The relationship between $90 \%$ percentile inhibin A and PE

\begin{tabular}{|l|l|l|l|}
\hline \multirow{2}{*}{ Preeclampsia } & \multicolumn{3}{|c|}{$90 \%$ percentile of inhibin A } \\
\cline { 2 - 4 } & $>329$ & $<329$ & Total \\
\hline Yes & 3 & 11 & 14 \\
\hline No & 25 & 261 & 268 \\
\hline Total & 28 & 272 & 300 \\
\hline \multicolumn{4}{|c|}{$\mathrm{p}=0.132$} \\
\hline
\end{tabular}

Table 5. Table of the correlation between inhibin A MOM $\geq 1.25$ and severe PE with gestational hypertension

\begin{tabular}{|l|l|l|l|l|l|}
\hline Variable & Level of inhibin A & MOM $\geq 1.25$ & MOM $<1.25$ & Total & p-value \\
\hline \multirow{3}{*}{ Severe preeclampsia } & Yes & $7(2.3 \%)$ & $1(0.3 \%)$ & $8(2.7 \%)$ & 0.004 \\
\cline { 2 - 5 } & No & $100(33.3 \%)$ & $192(64 \%)$ & $292(97.3 \%)$ & \\
\cline { 2 - 5 } & Total & $107(35.7 \%)$ & $193(64.3 \%)$ & $300(100 \%)$ & \\
\hline \multirow{3}{*}{ Gestational hypertension } & Yes & $2(0.7 \%)$ & $4(1.3 \%)$ & $6(2 \%)$ & 0.643 \\
\cline { 2 - 5 } & No & $105(35 \%)$ & $189(63 \%)$ & $294(98 \%)$ & \\
\cline { 2 - 5 } & Total & $107(35.7 \%)$ & $193(64.3 \%)$ & $300(100 \%)$ & \\
\hline
\end{tabular}

Table 6. The relationship between inhibin A level and pregnancy variables

\begin{tabular}{|l|l|}
\hline Evidence of severity of preeclampsia & p-value* \\
\hline Gestational age less than 37 weeks & 0.722 \\
\hline Transaminases more than twice the normal value & 0.357 \\
\hline Platelet less than 100,000 & 0.357 \\
\hline Headache & 0.001 \\
\hline Blurred vision & 0.357 \\
\hline Epigastric pain & 0.045 \\
\hline Nausea and vomiting & 0.009 \\
\hline Infant weigh less than 2,500 grams & 0.138 \\
\hline Serum LDH 1.5 times the normal value & 0.357 \\
\hline Constraint of intrauterine growth & 0.056 \\
\hline 3+ urine protein & 0.352 \\
\hline Systolic blood pressure equal to or greater than $160 \mathrm{~mm} \mathrm{Hg}$ & 0.191 \\
\hline Diastolic blood pressure equal to or greater than $110 \mathrm{~mm} \mathrm{Hg}$ & 0.618 \\
\hline
\end{tabular}

* All p-values were measured by Fisher's exact test.

\section{Discussion}

The outbreak of PE in this study was $4.66 \%$, which is less than its prevalence in other studies, which may be due to the selection of the population and the elimination of underlying factors. The results of this study showed that the level of inhibin A is connected to the incidence of PE and its severity $(p=0.0001$ and $p=0.004$, respectively). Other 
studies confirmed the relationship between inhibin A and PE, $(16,17)$. Muttukrishna et al. (16) studied the levels of inhibin A in 20 women with PE and 20 women with normal pregnancies who were in line in terms of the gestational age and parity and maternal age with the case group. The authors pointed out that the mean serum level of inhibin A in patients with normal blood pressure was $0.36 \mathrm{ng} / \mathrm{ml}$, while in PE patients it was $3 \mathrm{ng} / \mathrm{ml}$. In the study by $\mathrm{H}$. Laivuori et al. (17), which was on pregnant women in the third trimester, the authors confirmed that activin A, inhibin A, and Pro-alpha C significantly increased in PE. The mean level of inhibin A in the normal blood pressure in this study was $882 \mathrm{ng} / \mathrm{L}$; but in the PE group, it was $1691 \mathrm{ng} / \mathrm{L}(\mathrm{p}<0.003)$. The researchers concluded that increased levels of these markers are also related to proteinuria $(p<0.002)$. In this study, at odds to the findings of the study above, no relationship was found between the level of inhibin $A$ and proteinuria $+3(p=0.352)$. The reason for this can be due to the difference in the definition of variables in the two studies. In the present study, inhibin A level was taken into account as a discrete variable and its positive or negative relation with the rate of proteinuria +3 and higher was measured in patients. However, in the above study, the relationship between levels of inhibin A with proteinuria was continuously measured. In the present study, there was a significant relationship between headache and nausea and vomiting with PE severity symptoms. Moreover, in this study, the sensitivity of inhibin A in diagnosing PE was $73 \%$, which was $83.83 \%$ in our study, which was in line with similar studies in terms of sensitivity (18). Moreover, in the present study, the positive predictive value of inhibin A was $4.67 \%$ in the prediction of PE and $99.48 \%$ negative predictive value. This proves that the serum level of inhibin A is more useful and accurate in identifying healthy individuals and taking them out of a steady monitoring process than in identifying patients. According to the findings, the mean level of inhibin A in patients without PE was 203.88 \pm 89.79 $\mu \mathrm{g} / \mathrm{ml}$ and in PE patients $283.78 \pm 97.97 \mu \mathrm{g} / \mathrm{ml}$. These two did not have statistically significant differences. Furthermore, $90 \%$ percentile of serum levels of inhibin A could not predict the incidence of PE. Unlike the present study, in their study; Krissada et al. (18) signified that the mean serum level of inhibin A in PE patients (1229 pg/ml) was significantly $(\mathrm{p}=0.002)$ higher than those with normal blood pressure $(839 \mathrm{pg} / \mathrm{ml})$. The present study bore another finding too, which was the significant relationship between the level of inhibin A in the blood sample of pregnant women during the second stage screening with severe $\mathrm{PE}(\mathrm{P}=0.004)$. This was similar to the findings of Vorapong et al. (19) who examined inhibin A in the third trimester to evaluate the severity of PE. In their study, they found that levels of inhibin A increased with increased severity of PE. In comparison with pregnant women with normal blood pressure, MOM of inhibin A was 1.24 and 1.79, respectively, in mild and severe PE patients. The mean serum level of inhibin A in patients with severe PE was significantly higher than in mild PE group. However, in another study examining the levels of inhibin A in patients with PE or gestational pressure compared with control groups with normal blood pressure, Silver et al. (20) observed the overlap of inhibin A level in the case and control group. In this study, though there was a significant increase in serum levels of inhibin A in patients with severe PE, there was an overlap between subgroups of mild and severe PE. Thus, they concluded that the level of inhibin A is not useful in differentiating the mild and severe form of inhibin A. This overlap is seen in the study of Krissada et al. (18) and Vorapong et al. (17) as well. The difference between the stage of the start of PE, the genetic field, or the volume of samples in these studies may justify these differences. Regarding the study limitation, the small sample size of our study was potential limitation. It is suggested that further research be conducted prospectively with large sample size.

\section{Conclusions}

Based on the present research, one can conclude that the MOM of serum level of inhibin A in the blood sample of pregnant women during second stage screening can be effective and predict the occurrence of PE and severe PE. Nonetheless, this marker is ineffective in predicting pregnancy blood pressure. However, using this serum marker in the series of second-stage screening test, one can determine PE risk initially in pregnant women and improve maternal and infant health prospects via this with special obstetric care in pregnant women at higher risk.

\section{Acknowledgments:}

This study was extracted from an MD thesis of Atefeh Mazidi with No. 9401321907 and the authors would like to thank the financial support of the Vice Chancellor for Research and Technology of Urmia University of Medical Science and also, the cooperation of the student research committee and especially of the individuals participating in the study.

\section{Conflict of Interest:}

There is no conflict of interest to be declared.

Authors' contributions:

All authors contributed to this project and article equally. All authors read and approved the final manuscript. 


\section{References:}

1) Dashe JS HB, Mahendroo MS, Alexander JM, Sheffield JS, Casey BM. Williams Obstetrics. 24nd ed. New York: McGraw-Hill; 2014.

2) Gabbe SG, Niebyl JR, Galan HL, Jauniaux ER, Landon MB, Simpson JL, et al. Obstetrics: normal and problem pregnancies: Elsevier Health Sciences; 2012.

3) Phupong V, Dejthevaporn T, Tanawattanacharoen S, Manotaya S, Tannirandorn Y, Charoenvidhya D. Predictingthe risk of preeclampsia and small for gestational age infants by uterine artery Doppler in lowrisk women. Arch Gynecol Obstet. 2003; 268(3): 158-61. doi: 10.1007/s00404-002-0361-0. PMID: 12942242 .

4) Wyatt SN, Rhoads SJ, Green AL, Ott RE, Sandlin AT, Magann EF. Maternal response to high-risk obstetric telemedicine consults when perinatal prognosis is poor. Aust N Z J Obstet Gynaecol. 2013; 53(5): 494-7. doi: 10.1111/ajo.12094. PMID: 23635010.

5) Knight PG. Roles of inhibins, activins, and follistatin in the female reproductive system. Front Neuroendocrinol. 1996; 17(4): 476-509. doi: 10.1006/frne.1996.0013. PMID: 8905350.

6) Birdsall M, Ledger W, Groome N, Abdalla H, Muttukrishna S. Inhibin A and activin A in the first trimester of human pregnancy. J Clin Endocrinol Metab. 1997; 82(5): 1557-60. doi: 10.1210/jcem.82.5.3934. PMID: 9141549.

7) Fowler PA, Evans LW, Groome NP, Templeton A, Knight PG. A longitudinal study of maternal serum inhibin-A, inhibin-B, activin-A, activin-AB, pro-alphaC and follistatin during pregnancy. Hum Reprod. 1998; 13(12): 3530-6. doi: 10.1093/humrep/13.12.3530. PMID: 9886545.

8) Muttukrishna S, North RA, Morris J, Schellenberg JC, Taylor RS, Asselin J, et al. Serum inhibin A and activin A are elevated prior to the onset of pre-eclampsia. Hum Reprod. 2000; 15(7): 1640-5. doi: 10.1093/humrep/15.7.1640. PMID: 10875882.

9) Muttukrishna S, Child TJ, Groome NP, Ledger WL. Source of circulating levels of inhibin A, pro alpha Ccontaining inhibins and activin A in early pregnancy. Hum Reprod. 1997; 12(5): 1089-93. doi: 10.1093/humrep/12.5.1089. PMID: 9194671.

10) Florio P, Cobellis L, Luisi S, Ciarmela P, Severi F, Bocchi C, et al. Changes in inhibins and activin secretionin healthy and pathological pregnancies. Mol cell endocrinol. 2001; 180(1-2): 123-30. doi: 10.1016/S0303-7207(01)00503-2. PMID: 11451581.

11) Reis FM, D’Antona D, Petraglia F. Predictive value of hormone measurements in maternal and fetal complications of pregnancy. Endocr Rev. 2002; 23(2): 230-57. doi: 10.1210/edrv.23.2.0459. PMID: 11943744.

12) Florio P, Luisi S, Ciarmela P, Severi FM, Bocchi C, Petraglia F. Inhibins and activins in pregnancy. Mol Cell Endocrinol. 2004; 225(1-2): 93-100. doi: 10.1016/j.mce.2004.02.018. PMID: 15451573.

13) El-Gharib MN, Morad M. Maternal serum inhibin-A for predicting preeclampsia. J Matern Fetal Neonatal Med. 2011; 24(4): 595-9. doi: 10.3109/14767058.2010.511345. PMID: 21375372.

14) Prats P, Rodríguez I, Nicolau J, Comas C. Early first-trimester free- $\beta$-hCG and PAPP-A serum distributions in monochorionic and dichorionic twins. Prenat Diagn. 2012; 32(1): 64-9. doi: 10.1002/pd.2902. PMID: 22367671.

15) Redman CW, Sargent IL. Pre-eclampsia, the placenta and the maternal systemic inflammatory response--a review. Placenta. 2003; 24 Suppl A: S21-7. doi: 10.1016/0143-4004(91)90339-H. PMID: 12842410.

16) Muttukrishna S, Hyett J, Paine M, Moodley J, Groome N, Rodeck C. Uterine vein and maternal urinary levels of activin A and inhibin A in pre - eclampsia patients. Clin Endocrinol (Oxf). 2006; 64(4): 469-73. doi: 10.1111/j.1365-2265.2006.02476.x. PMID: 16584522.

17) Laivuori H, Kaaja R, Turpeinen U, Stenman UH, Ylikorkala O. Serum activin A and inhibin A elevated in pre-eclampsia: no relation to insulin sensitivity. Br J Obstet Gynaecol. 1999; 106(12): 1298-303. doi: 10.1111/j.1471-0528.1999.tb08185.x. PMID: 10609725.

18) Paiwattananupant K, Phupong V. Serum inhibin A level in preeclampsia and normotensive pregnancy. Hypertens Pregnancy. 2008; 27(4): 337-43. doi: 10.1080/10641950802020545. PMID: 19003635.

19) Phupong V, Paiwattananupant K, Honsawek S. Inhibin A levels and severity of preeclampsia. Arch Gynecol Obstet. 2009; 280(2): 183-6. doi: 10.1007/s00404-008-0886-y. PMID: 19107499.

20) Silver HM, Lambert-Messerlian GM, Reis FM, Diblasio AM, Petraglia F, Canick JA. Mechanism of increased maternal serum total activin a and inhibin a in preeclampsia. J Soc Gynecol Investig. 2002; 9(5): 308-12. doi: s10.1177/107155760200900509. PMID: 12383916. 